\title{
MIDAS
}

Museus e estudos interdisciplinares

$11 \mid 2020$

Dossier temático: "Perspetivas sobre o museu eclético"

\section{Páginas da vida de um jovem arqueólogo: Francisco Tavares Proença Júnior (1883-1916)}

Pages of the life of a young archaeologist: Francisco Tavares Proença Júnior (1883-1916)

\section{Ana Cristina Martins}

\section{OpenEdition}

\section{Journals}

\section{Edição electrónica}

URL: http://journals.openedition.org/midas/2141

DOI: $10.4000 /$ midas. 2141

ISSN: 2182-9543

\section{Editora:}

Alice Semedo, Paulo Simões Rodrigues, Pedro Casaleiro, Raquel Henriques da Silva, Ana Carvalho

\section{Refêrencia eletrónica}

Ana Cristina Martins, « Páginas da vida de um jovem arqueólogo: Francisco Tavares Proença Júnior (1883-1916) », MIDAS [Online], 11 | 2020, posto online no dia 19 novembro 2020, consultado no dia 21 novembro 2020. URL : http://journals.openedition.org/midas/2141 ; DOI : https://doi.org/10.4000/ midas. 2141

\section{Este documento foi criado de forma automática no dia 21 novembro 2020}

\section{cc) (1) (ㅇ)}

Midas is licensed under a Creative Commons Attribution-NonCommercial-ShareAlike 3.0 International License 


\section{Páginas da vida de um jovem arqueólogo: Francisco Tavares Proença Júnior (1883-1916)}

Pages of the life of a young archaeologist: Francisco Tavares Proença Júnior (1883-1916)

\section{Ana Cristina Martins}

\section{NOTA DO EDITOR}

Artigo recebido a 12.02.2019

Aprovado para publicação a 15.03.2020

Agradecimentos: À Joana d'Oliva Monteiro, por toda a compreensão, por todo o apoio e pela amizade.

[...] tão útil como uma escola pois nas sãs vitrines, melhor do que nas páginas e figuras mudas dos

livros,

nós aprendemos a conhecer-nos a nós mesmos e a conhecer e a amar o passado da pátria. (Materiaes, anno I, Setembro-Outubro 1910, n. 2, itálicos da autora)

\section{A arqueologia em Portugal em finais de Oitocentos}

Quando Francisco Tavares Proença Júnior (1883-1916) nasceu, a arqueologia em Portugal transfigurara-se profundamente num Portugal, ainda Regenerador, onde as questões patrimoniais suscitavam debates e geravam expectativas, ao mesmo tempo 
que desconfianças, designadamente por quem entrevia nos estudos pré-históricos uma perigosa anteposição às Sagradas Escrituras. ${ }^{1}$

2 Três anos antes (1880), Lisboa acolhera, nas instalações da Academia Real das Ciências (ARC) (1779), com a presença de membros da Casa Real e minuciosa cobertura diária por parte da imprensa nacional, a nona sessão do Congrès International d'Anthropologie et d'Archéologie Préhistorique (CIAAP), num momento de particular significado para um país que comemorava o centenário camoniano apoiado pelo (ainda) embrionário movimento republicano português. Movimento que não era estranho à importância dos estudos pré-históricos na afirmação da vontade e da criatividade individuais como elementos fundamentais da evolução e do progresso humanos, como ficara patente na Galérie du Travail da Exposição Universal de Paris de 1867 (Carnino 2015).

3 Fundado em 1865, por Gabriel de Mortillet (1821-1898), o CIAAP fora assumido como fórum principal de produção de conhecimento, debate científico e definição de metodologias de trabalho nas duas áreas contempladas. Incontornável para quem se dedicava ao estudo do passado mais remoto da Humanidade, o Congresso congregava amiúde representantes de diversos países europeus em torno de temas tão díspares quanto a uniformização de signos utilizados em mapas arqueológicos e a salvaguarda de estruturas pretéritas. Idealizado e liderado por aquele reconhecido antropólogo e préhistoriador francês, o CIAAP cumpria uma das suas funções oficiosas ao reforçar o domínio científico da França numa Europa que assistia à gradual, porém assertiva, afirmação alemã sustida por uma agenda geopolítica prussiana (Sommer 2009).

4 A capital portuguesa tivera, por conseguinte, a oportunidade única de receber importantes antropólogos e pré-historiadores europeus, muitos dos quais afiliados em instituições de referência das disciplinas abarcadas pelo CIAAP. Animados com a perspectiva de que o êxito da sua realização fomentasse o crescimento da arqueologia no país, os ainda poucos cultores destas duas ciências, entre nós, como Carlos Ribeiro (1813-1882), Francisco Martins Sarmento (1833-1899) e Possidónio da Silva (1806-1896), não mediram esforços para que tudo decorresse com a qualidade exigida e aguardada. Por isso elaboraram um intenso e aliciante programa científico e social rememorado por participantes estrangeiros em longas crónicas e opúsculos (Congrès 1884).

5 Encerrados, porém, os trabalhos do Congresso, a esperança desvaneceu-se quase num ápice. Por exemplo, o futuro "Museu Arqueológico do Algarve" programado por Estácio da Veiga (1828-1891), autor da primeira carta arqueológica no país, após ser parcialmente exposto no claustro da ARC, era encaixotado para ver de novo a luz do dia somente em finais do século, graças a um protagonista nuclear da arqueologia em Portugal, José Leite de Vasconcelos (1858-1941).

6 Esmorecia-se assim o sonho de muitos, quebrantado com a morte inesperada de Carlos Ribeiro, pioneiro dos estudos pré-históricos no território, no quadro da intermitente Comissão Geológica $(1848,1857)$, e a quem se devia, em boa medida, a realização do CIAAP em Lisboa. Um desalento feito clarividência quanto à especificidade do nosso país nesta matéria, e que suscitou uma imediata reaç̧ão por parte de entidades privadas que se dedicavam aos estudos arqueológicos, a exemplo da Real Associação dos Arquitectos Civis e Arqueólogos Portugueses (Lisboa, 1863). Fortaleceram-se então iniciativas preexistentes e promoveram-se novas acções materializadas em escavações, colecções, espaços museológicos, sociedades eruditas - como a Sociedade Martins Sarmento (SMS) (Guimarães, 1881) -, cursos e publicações da especialidade. 
7 Mas a forma como os congressistas foram acolhidos; a excelência do programa científico e social do encontro; as visitas realizadas a colecções, museus e sítios arqueológicos de Lisboa e fora da capital; o acompanhamento diário das sessões de trabalho por parte da imprensa diária encorajaram quem confiava assistir ao reconhecimento definitivo da ciência arqueológica no país, através da sua inserção definitiva no meio académico e universitário. De contrário, a imagem do país sairia desprestigiada, sendo por isso (quase) impensável que a presença de tão reputados investigadores europeus fosse totalmente inconsequente para o país.

8 Apesar de frustrados neste seu intento primacial, parte da organização do encontro animou com a solicitação governamental dirigida, ainda neste ano, à RAACAP para que listasse estruturas antigas a merecer classificação como "monumento nacional", à semelhança do que sucedia noutros países, como em França, através da Commission des Monuments Historiques (1837). Tratou-se, na verdade, de pedido eloquente quanto ao prestígio granjeado por esta agremiação e à improficiência estatal no assunto. Entregue poucos meses depois, graças à ampla rede de sócios correspondentes que a RAACAP vinha compondo há muito, o relatório deu lugar à Comissão dos Monumentos Nacionais $(1881)^{2}$, o primeiro organismo de salvaguarda patrimonial instituído no país (Martins 2003 e 2005; Custódio 2013).

9 Na verdade, o CIAAP de 1880 demonstrou, ou reiterou, o alheamento quase total das autoridades centrais portuguesas em relação à importância da investigação arqueológica. Um aparente desprendimento que fundamentou, por exemplo, o regresso do antropólogo e arqueólogo Émile Cartailhac (1845-1921) ao nosso território, auxiliado por um subsídio do Estado francês, para, após visitar e estudar colecções, museus e sítios, publicar Les Ages Pré-historiques de l'Espagne et du Portugal (Paris, 1886), obra de referência até à actualidade (Dubois 2011).

10 Não obstante, os primeiros momentos de desalento deram lugar a alguma expectativa, com a criação, cinco anos depois, de uma nova cadeira na Universidade de Coimbra, de Antropologia, Paleontologia Humana e Arqueologia Pré-histórica, conquanto no quadro dos estudos zoológicos. Quase em simultâneo, a RAACAP inaugurava, na sua sede, o 1.ำ Curso Elementar de Arqueologia (1885) (Museu Arqueológico do Carmo, Lisboa), frequentado por representantes de várias faixas etárias, classes sociais e profissionais, e cujo sucesso justificou uma segunda edição (1887) (Martins 2003). Mas, uma vez mais, era a iniciativa privada - quantas vezes unipessoal -, a trilhar um caminho por vezes solitário perante o desinteresse estatal. Cientes, porém, da sua imprescindibilidade, seguros das suas ideias e convictos das suas decisões, não cederam, mesmo quando cumulavam desilusões.

11 Relembremos, no entanto, como Portugal mergulhara numa profunda indignação provocada pelas humilhantes pretensões estrangeiras lançadas sobre domínios ultramarinos portugueses, principalmente africanos, desde a Conferência de Berlim (1884-1885) ao Ultimatum inglês, (1890), enquanto os Vencidos da Vida realçavam o falhanço da modernização do país num período de acentuadas tensões políticas registadas nos reinados de D. Luís I (1838-1889) e de D. Carlos I (1863-1908). Com efeito, Portugal enfrentava uma grave crise financeira geradora de movimentações comunistas, anarquistas, republicanas e carbonárias, mesmo quando procurava ultrapassar o atraso agrícola, industrial e comercial.

12 Entregues, quase na totalidade, a si mesmos e aos seus projectos, os cultores da arqueologia semeavam ideias para que a letargia e o caciquismo epidémico não 
fizessem vingar a indiferença, evitando que o desapreço político, a ignorância popular e o abandono de intelectuais consumidos pela ineficiência das suas crónicas não sufocassem o bem comum. Insistiram, por isso, no estudo do passado de localidades e regiões, na formação de colecções, na criação de museus, na instituição de instrumentos de preservação patrimonial, na fomentação do associativismo local e na publicação de periódicos e monografias.

13 Tudo, ou quase tudo, alcançado mercê de vontades individuais e de alguns (raros) apoios locais. Mas também muito graças ao compromisso de quem, como os dirigentes da RAACAP, pretendia ampliar o seu projecto patrimonial aos mais ínfimos recantos do país, inspirados pelo modo como o CIAAP de 1880 animara estetas e literatos a prospectar, escavar, coleccionar, musealizar, escrever e palestrar. Disso é testemunho o Museu Municipal da Figueira da Foz, estabelecido em 1894 por determinação de António dos Santos Rocha (1853-1910) ("DR. ANTONIO dos Santos Rocha" 1910; Martins 2012), descerrando um novo capítulo da investigação histórica, artística e arqueológica da região, consolidado na Sociedade Arqueológica da Figueira (1898).

14 Não obstante, parecia que apenas uma individualidade deteria, à época, a capacidade, a tenacidade e o sentido de oportunidade suficientes para estruturar um plano mais dilatado, contudo indispensável a um país que almejava manter-se na vanguarda ocidental: José Leite de Vasconcelos. Esta personalidade ditou, sem dúvida, parte substantiva do futuro da arqueologia portuguesa num momento em que F. Tavares Proença Júnior se transformava em jovem adulto (Coito 1999).

\section{A formação inicial do futuro arqueólogo}

Analisar a obra de Francisco Tavares Proença Júnior constitui uma oportunidade de elaborar uma biografia intelectual, contextualizando, a vários títulos, decisões, procederes e resultados (Martins 2016) (fig. 1). 


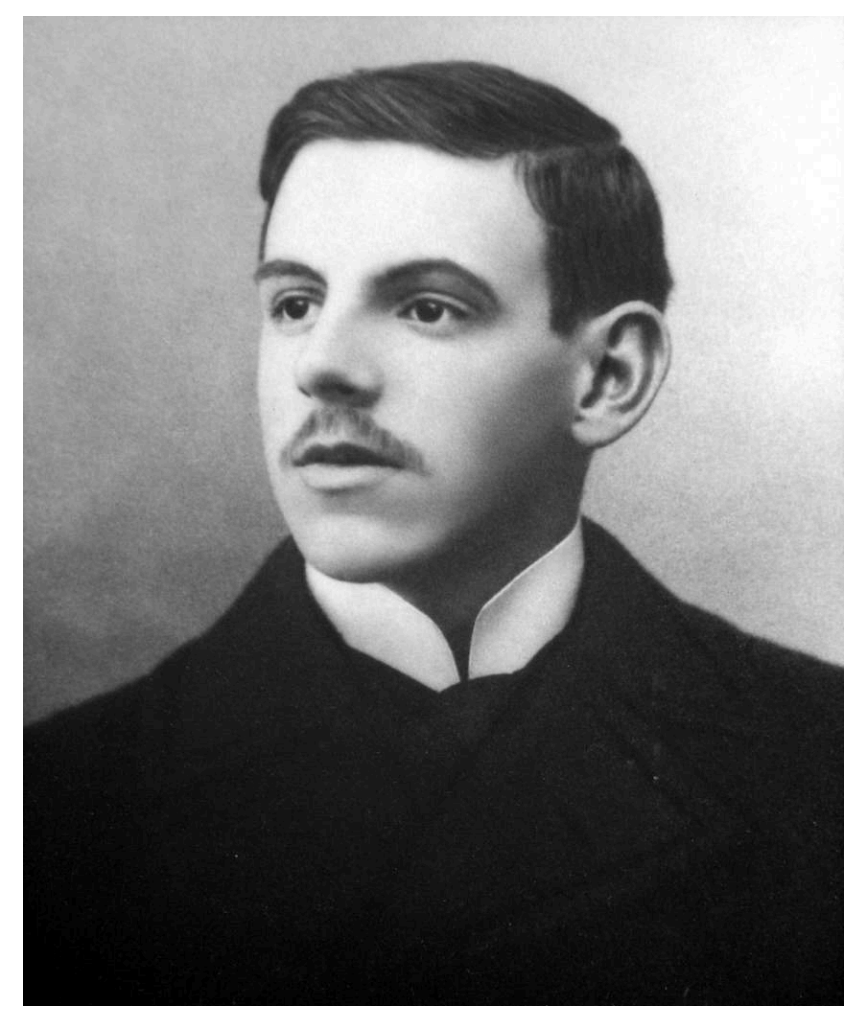

Fig. 1 - Francisco Tavares Proença Júnior (1883-1916)

Fonte: Diário Digital Castelo Branco

16 Além disso, esta figura ímpar da arqueologia finissecular portuguesa permite desmontar a ideia ainda presente nalguma historiografia quanto ao carácter periférico - se não isolado -, de cidades como Castelo Branco, em relação a conhecidos epicentros políticos, económicos e culturais, como Lisboa, Coimbra e Porto (Papanelopoulou, Nieto-Galan e Perdiguero 2009). Visão, na verdade, redutora e pouco consentânea com a realidade observada em periódicos regionais da época e na correspondência (incluindo internacional) ${ }^{3}$ mantida entre intelectuais que comungavam, por exemplo, de formações académicas obtidas na Universidade de Coimbra ou em cursos superiores e politécnicos de Lisboa e Porto. Dever-se-á, sem dúvida, rever o conceito de "periferia científica" (Papanelopoulou, Nieto-Galan e Perdiguero 2009), incluindo a arqueológica, relembrando, para o efeito, casos como o da Société des Antiquaires de Normandie (1824) fundada por Arcisse de Caumont (1801-1873). Este e outros testemunhos demonstram como as elites locais e regionais se empenhavam em escrutinar o pretérito dos respectivos territórios, formando sociedades e ultrapassando barreiras, incluindo geográficas, que pudessem obstar à circulação de conhecimento e à afirmação de estratégias individuais e colectivas.

Portugal confirmou este processo. Fora Setúbal e não Lisboa a produzir o primeiro grupo de investigação arqueológica, a Sociedade Archeologica Luzitana (1849-1857) (SAL) (1849) (Martins 2014). A perda, porém, de mecenas e a descontinuidade dos apoios políticos, num período vincado pela Regeneração (1851-1865), expansão africana e regência de D. Fernando II (1816-1885), ditou o seu rápido desenlace. Não que a agenda liberal desconsiderasse o desenvolvimento cultural. Ao contrário, projectava a reforma do ensino (incluindo o superior), estimulava a ciência e a tecnologia e incentivava os estudos técnicos, industriais e artísticos. Por isso se multiplicou o número de 
bibliotecas, salas de leitura e laboratórios; se favoreceu e diversificou a impressa; se aumentou o número de palestras públicas. Mas, no tocante ao património edificado e móvel, e apesar da acção meritória da Academia Real de Belas-Artes de Lisboa (1836), eram sobretudo as poucas sociedades eruditas então existentes a cuidá-lo, apoiadas, com alguma frequência, por elites locais e regionais.

\section{Entre Inglaterra e Coimbra: o interesse pela arqueologia}

18 Nascido em família de longa tradição albicastrense, detentora de grande casa agrícola e prestígio social e político, F. Tavares de Proença Júnior foi enviado, com 16 anos, para um colégio interno na ilha de Wight, Grã-Bretanha. Aqui se entusiasmou pela prática da educação física, pelo estudo das ciências naturais e pela antiguidade do território presente em colecções e museus, um apreço reforçado em Londres com a visita ao British Museum e à National Gallery.

Regressado de férias a Portugal, não mais retornou à Ilha de Wight devido a infecção pulmonar que o conduziu até uma clínica em Davos, Suíça, e à Serra da Estrela. Aqui mergulhou em leituras históricas, artísticas e arqueológicas, enquanto calcorreava os seus recantos mais ásperos em busca de elementos ancestrais, mormente megalíticos (Proença Júnior 1910; Cardoso 2001 e 2008; Henriques 2004; Martins 2009b; Caninas 2012). Terá decidido então consagrar a sua vida à arqueologia, interessado pelo pouco que se conhecia da pré-medievalidade da Beira Interior, em especial da região albicastrense. Escrutinando e divulgando o território onde residia e tinha raízes, tornar-se-ia assim precursor do seu estudo e difusão (Henriques et al. 2015). 0 pai tinha, contudo, outros planos e por isso o fez ingressar na Faculdade de Direito da Universidade de Coimbra.

\section{A Serra da Estrela na constância de ser arqueólogo}

Contrariado no destino que o peso dos sobrenomes lhe reservou, F. Tavares Proença Júnior assumiu publicamente o seu gosto pela arqueologia em 1903 ao entrar no Instituto de Coimbra (IC) (1852), por mão de Bernardino Machado (1851-1944), onde Augusto Filipe Simões (1835-1884) apadrinhara (1873) a criação de uma secção e de um museu de arqueologia. Entretanto, aproveitava as férias estivais no Sanatório da Covilhã para atravessar terrenos e localidades em demanda de estruturas e inscrições antigas, algumas delas reproduzidas em cadernos de apontamentos. Por esta mesma altura, redige um pequeno artigo publicado no volume 50 da revista Instituto e o opúsculo Antiguidades. I. Resultado de explorações feitas nos arredores de Castello Branco em Setembro e Outubro de 1903, também ele dado à estampa em Coimbra.

Neste, revela como, aos 20 anos de idade, coleccionava artefactos recolhidos nas suas investigações - por escavação, doação ou compra -, em grande parte graças à excelente rede de contactos pessoais e familiares que mantinha, acrescida de um importante conjunto de informadores locais que mantinha e engrandecia (Martins 2016). Eram materiais que, já então, pretendia colocar em Castelo Branco, á disposição de todos aquelles que desejarem observá-los. Por isso também continuou a indagar o território albicastrense e a viajar até Lisboa, observando com acuidade objectos expostos em 
museus como o Arqueológico do Carmo (1864), pertença da RAACAP. Neste período, publica ainda o resultado das suas explorações inicialmente centradas na tipologia megalítica, ao mesmo tempo que concebe um modelo de ficha de inventário que haveria de facilitar a caracterização dos exemplares por ele encontrados e recolhidos.

É na sequência destas actividades que virá a participar pela primeira vez num fórum internacional da especialidade: o I Congrès Préhistorique de France promovido pela Société Préhistorique de France (Paris, 1904), realizado em Périguex no ano de 1905. Representando oficialmente o IC, por indicação do respectivo Presidente (Bernardino Machado), F. Tavares Proença Júnior visita o Museu Archeologico de Madrid na sua viagem de regresso à capital portuguesa, nele procurando analogias tipológicas para artefactos da sua colecção. Já em Portugal, continuou a intercalar a sua permanência coimbrã com viagens de curta duração a regiões nortenhas mapeadas no exercício da arqueologia no país. Era o caso de Guimarães, graças à exemplaridade do trabalho ali realizado pela SMS, mas também do Porto e da Figueira da Foz. Proença Júnior não se limitava, contudo, ao Norte do território, transitando de igual modo pelos termos de Portalegre e Évora, onde consegue engrandecer a sua própria colecção arqueológica. A propósito destas jornadas, viria a recordar: «Eu tenho-me visto ali [Castelo Branco] absolutamente só, nem uma única pessôa que me auxilie, além dos dedicados operarios que trabalham à minha vista e sob a minha direcção». ${ }^{4}$

Entretanto, o ano de 1906 é, sem dúvida, crucial na vida de F. Tavares Proença Júnior. Participando de novo num congresso em França (Congrès 1907) e publicando no 53.ำ volume da revista Instituto, comunica ao pai o desejo de cursar Letras em Lisboa ou Filosofia em Coimbra, de cuja Universidade sairá definitivamente em 1907, ano dos efervescentes protestos académicos de 28 de Fevereiro (Gonçalves 2007).

\section{Do adeus a Coimbra à inauguração do Museu Municipal de Castelo Branco}

Não conseguindo, por oposição paternal, transferir-se para o Curso Superior de Letras a funcionar nas instalações da Academia Real das Ciências, no coração de Lisboa, F. Tavares Proença Júnior passou a conciliar os deveres impostos pelo pai com os estudos arqueológicos. Por isso, enquanto a Universidade permanecia encerrada por ordem do Presidente do Conselho e Ministro do Reino, João Franco (1855-1929), o jovem arqueólogo recuperava, com maior cadência, as investigações no terreno, localizando, identificando e desenhando (mesmo que parcialmente) sítios arqueológicos e (re)visitando colecções e museus. Estas deambulações eram alternadas com momentos de escrita e de publicação, como as Inscripções Romanas de Castello Branco publicadas em 1907 por iniciativa do Museu Etnológico Português (MEP) (1893), em reconhecimento do seu trabalho.

No cômputo geral, tais acções tê-lo-ão persuadido da pertinência de criar um museu arqueológico em Castelo Branco. Ideia que poderá ter brotado enquanto adquiria artefactos para a sua colecção, observava exemplos nacionais, como os de F. Martins Sarmento e de A. Santos Rocha, e confirmava o importante papel que um recurso desta natureza podia e devia desempenhar no desenvolvimento cultural das regiões e suas gentes. 
26 Não surpreende, por conseguinte, que F. Tavares Proença Júnior abraçasse o desígnio dos ideários finisseculares, metamorfoseando um prazer algo solitário num bem público ao serviço da comunidade, neste caso de Castelo Branco, epicentro das suas actividades arqueológicas e terra de seus antepassados paternos. Circunstância que adquiria outra dimensão ao ter sido um pioneiro consequente na observação metódica dos seus termos em busca de indícios da sua mais antiga história, inventariando-os, resgatando-os e divulgando-os por diversos meios, para assim preencher lacunas deixadas em aberto por iniciativas anteriores, como a da expedição scientifica organizada pela Sociedade de Geografia de Lisboa (1875) à Serra da Estrela, em 1881.

Mas a ideia de um museu em Castelo Branco surgiu-lhe muito antes da sua presença nos congressos franceses. Nas suas próprias palavras, dirigidas ao pai em 1909, F. Tavares Proença Júnior refere tê-la concebido cerca de sete anos antes, ou seja, em 1902. Coincidira, por conseguinte, com as suas primeiras prospecções no terreno (vide supra) e o início da sua colecção $0^{5}$, pois, «Ainda, um dia, Castello Branco há-de ter um Museu Municipal e ainda talvez um dia ahi se reunam os sabichões n'uma especie de Congresso Nacional de Archeologia! Já estive mais longe d'isso!» ${ }^{6}$. A mesma informação surge na correspondência enviada a J. Leite de Vasconcelos, no início de 1911:

[...] eu comecei em 1902 a reunir elementos para a fundação de um museu em C. Branco e comecei a reunir apontamentos e materiaes para num futuro proximo poder dizer o que podesse e o que estivesse adentro dos estreitos limites das minhas forças, a proposito das mais antigas civilizações d'esta região // É esse projecto que eu tenho teimado em realisar, embora á mercê de embaraços, de contrariedades de toda a especie, tanto da parte de minha familia como da parte dos meus amigos. ${ }^{7}$

Tomada a decisão e persuadido da sua pertinência e qualidade, delineou o projecto que endereçou de imediato à edilidade albicastrense, enquanto esperava que a rede de contactos paterna permitisse concretizá-lo com a maior celeridade possível. A verdade é que os acontecimentos se precipitaram de modo quase vertiginoso. Apresentado ao Presidente da Câmara Municipal, o advogado Manuel Pires Bento (1871-1939), a título meramente particular, o plano foi-lhe remetido dois dias depois, já de forma oficial ${ }^{8}$, para ser aprovado em sessão camarária de 8 de Abril de 1908, com a prerrogativa de o museu ser montado em 12 meses, a contar de 26 de Agosto desse mesmo ano.

Com o caminho aberto para realizar o seu projecto maior, havia que prosseguir, lendo, prospectando, obtendo mais exemplares para o novo espaço museológico e difundindo além-fronteiras as particularidades da arqueologia em Portugal. Por isso, conseguiu a entrada de objectos oferecidos para o futuro museu, fruto da sua vasta rede de contactos pessoais e familiares, enquanto endereçava informações ao pré-historiador e filho de G. de Mortillet, Paul de Mortillet, sobre o megalitismo no território nacional, folheava o Bulletin de la Société d'Excursions Scientifiques (1899-1935) e revisitava regiões para obtenção, através de oferta e compra, de mais objectos a depositar no novo museu (Martins 2016).

Porém, o prazo definido para a instalação do museu - Agosto -, aproximava-se velozmente. Chegado o momento e não se encontrando o museu instalado, corria-se o risco de o Ministério da Guerra retirar à Câmara Municipal a capela do Convento de Santo António dos Capuchos - então transformado em hospital militar -, disponibilizada para o efeito e apropriar-se das benfeitorias realizadas nela entretanto. Tratava-se de um receio legítimo porque nada fôra publicado sobre a sua cedência no Diário do Governo. Por isso mesmo, F. Tavares Proença Júnior solicitou ao pai que intercedesse pessoalmente junto do Ministro para que o termo de abertura fosse 
adiado, a fim de evitar o hipotético desvio da soma destinada às obras de requalificação daquele espaço. Era uma prorrogação indispensável, por exemplo, à aquisição de vitrinas adequadas à exposição de materiais de menor dimensão e à adaptação da sacristia onde F. Tavares Proença Júnior planeara dispor a maior parte dos objectos.

Neste entretanto, F. Tavares Proença Júnior é nomeado director do futuro Museu por disposição camarária de Janeiro de 1910.

Após inúmeras peripécias, vários obstáculos e imprevistos, o Museu Municipal de Castelo Branco, organizado em secções (desde o paleolítico à pintura), é finalmente aberto ao público a 17 de Abril de 1910, na presença das principais autoridades albicastrenses $^{9}$ (Dias 1954, 9):

Outros [museus] serão melhores. 0 que poder apresentar n'aquelle devo-o a mim mesmo! E a mais ninguem! Nem uma única pessoa me ajudou até esta data! É extraordinario mas é verdade. Os objectos que exposer, achei-os eu no terreno em excursões, em explorações, etc., á minha custa foram transportados, eu n'elles collei as etiquetas, eu os heide dispôr nas vitrinas, eu, talvez, terei de limpar o pó das vitrinas no dia de abertura do Museu! (“Epistolário de José Leite de Vasconcelos”. 2776 - Júnior, Francisco Tavares Proença, 19253 4/5 e 5/5. 13 de Outubro de 1909, itálicos da autora)

Visitável aos domingos, entre as 10 h00 e as 16 h00, o museu compunha-se «...de productos industriaes que nos foram deixados pelas differentes civilisações que se estabeleceram na Lusitania...», desde os Tempos préhistóricos ao Periodo histórico. Para o director da nova instituição, o objectivo seria contribuir para contrariar o,

[...] mal dos nossos museus - expõem-se objectos etiquetados e numerados e raros são os relatórios que se publicam, indicando todas as circunstancias da exploração, se é que a maior parte das vezes essas circumstancias são notadas e archivadas pelos exploradores. Todos os elementos que principalmente deviam ser recolhidos, os únicos que realmente interessam a sciencia, perdem-se por completo ou desprezam-se para expor apenas os objectos absolutamente mudos e despidos muitas vezes de todo o interesse. (Materiaes 1910, n. 2, p. 4, itálicos da autora)

Já na qualidade de Director do Museu Municipal de Castelo Branco, etc., etc., e coroando um longo percurso, F. Tavares Proença Júnior deu à estampa Archeologia do Districto de Castello Branco (1..$^{a}$ contribuição para o seu estudo), onde repudiou precipitações observáveis em trabalhos contemporâneos, nomeadamente em «... Portugal aonde eu desejaria que observações methodicas feitas segundo o formidável rigor da sciencia moderna, e descripções minuciosas e completas - sem phraseados pomposos e estéreis - viessem confirmá-la ou regeitá-la [teorias várias]» (Materiaes 1910, n.․ 2, p. 4, itálicos da autora) (Fabião 2004; Antunes 2007).

Por isto, também, não bastava manter o museu aberto. Havia que escorar o projecto museológico com instrumentos que assegurassem a sua perpetuação, divulgando-o e tornando-o imprescindível, não apenas para a região onde se encontrava, como para a totalidade do território que integrava. Os recursos necessários à sua concretização acabaram por ser, uma vez mais, disponibilizados pelo pai, que viria a financiar a publicação da revista Materiaes, lançada três meses volvidos sobre a inauguração do Museu. Para o seu editor, esta publicação corresponderia a uma collecção de apontamentos (Proença Júnior 1908). Apontamentos em forma de materiaes. Materiaes para o estudo das antiguidades portuguezas, como subintitulou, numa fórmula positivista e análoga a outras edições, incluindo portuguesas ${ }^{10}$ :

Estou trabalhando, já há tempos, na preparação de uma revista modesta, qualquer coisa no genero de Mortillet, (L'Homme Prehistorique) e que será dividida em 3 
secções: - Literattura, Historia e Archeologia - Cada uma d'estas secções occupará 10 paginas e a revista sahirá de 2 em 2 mezes. Na elaboração da secção de archeologia seguirei, sempre que possivel, o caminho traçado por V. Ex. aㅗ nas Religiões da Lusitânia. ${ }^{11}$

Visando internacionalizá-la através de resumos dos textos em francês, a revista abrangia estudos históricos, artísticos, arqueológicos, etnográficos e antropológicos, aos quais acresciam recensões críticas a trabalhos editados:

As paginas d'esta revista serão em grande parte preenchidas pela Direcção. Em todo o caso, publicará sempre com preferência e jubilo quaesquer relatórios de achados ou explorações archeologicas que queiram enviar-lhe todos que se interessam pelos progressos da sciencia em Portugal. Quaesquer noticias de trabalhos realizados, descripções de objecos encontrados em explorações ou casualmente, simples informações de monumentos e objectos archeologicos de toda a espécie, copias de inscripções, elementos para o estudo de antigas sobrevivências, costumes, industrias e processos caseiros, superstições, lendas, tradições, etc., tudo será bemvindo. // [...]. Serão analysados todos os trabalhos de que nos seja enviado um exemplar, quer se apresentem sob a forma de livro, quer de publicação periódica. (Materiaes, anno I, Julho-Agosto 1910, n.ำ 1)

F. Tavares Proença Júnior ambicionava, simultaneamente, alicerçar ainda mais o projecto museológico, constituindo uma sociedade scientifica local. Uma sociedade que deveria ser composta das elites locais e regionais empenhadas no desenvolvimento da cidade e da região e ter o apoio municipal, considerando, nas suas palavras, que o museu era «... tão útil como uma escola pois nas sãs vitrines, melhor do que nas páginas e figuras mudas dos livros, nós aprendemos a conhecer-nos a nós mesmos e a conhecer $e$ a amar o passado da pátria» (Materiaes, anno I, Setembro-Outubro 1910, n. 2, itálico da autora).

Tratava-se, pois, de um programa assente em três pilares: museu, revista e sociedade erudita. Ou melhor, de um programa (= museu) a perpetuar com revista e sociedade erudita. Um desígnio definido com esperança e substanciado com firmezas regidas por uma vontade férrea de colocar Castelo Branco no mapa científico português e europeu, e os inúmeros capitais disponibilizados pelo contexto familiar. Mas não só.

Tardiamente reconhecido pelo pai e por este confrontado reiteradamente pelas opções e estilo de vida assumidos, é possível que F. Tavares Proença Júnior necessitasse, mesmo que de modo pouco ciente, deste percurso científico e museológico para se afirmar junto de seus pares, familiares e sociedade albicastrense. Neste sentido, poderemos estar perante uma estratégia concertada de afirmação individual por via da ciência e da cultura mercê da fruição de um forte capital social, económico e político de uma família que se confundia com o próprio território albicastrense e que nele mantinha redes fundamentais ao exercício idealizado por F. Tavares Proença Júnior.

Um exercício e um projecto de vida que pouco se coadunavam ao imperativo centralizador do MEP, com cujo director manteve uma relação dual de admiração e censura (Martins 2016). Mais do que isso, é provável que estejamos, como na Guimarães de F. Martins Sarmento, perante um plano de simbiose entre indivíduo, família, colecção, museu e identidade territorial e cultural. Melhor, de um território dominado por uma família representada no museu através de um dos seus membros. Um museu que interpretava - ao mesmo tempo que construía -, uma determinada unidade territorial identitária das suas gentes. Gentes fixadas ancestralmente a um determinado território ritmado por necessidades, objectivos e procedimentos de umas quantas famílias entrelaçadas genealogicamente. Tratar-se-ia, pois, de uma forma mais de 
(re)centralizar poderes e legitimar hierarquias através de uma nova narrativa: a museológica, firmada em metodologias científicas.

41 Independentemente de tais reflexões, o plano de um programa mais alargado revelouse efémero, ainda que não pela ausência de pertinência, qualidade dos contributos individuais, escassez de recursos e esmorecimento directivo. Fugaz, pela conjuntura vivida em 1910, culminando na implantação da República, a 5 de Outubro, o mês do segundo e último número da revista Materiaes, num momento em que F. Tavares Proença Júnior lamentou o recente desaparecimento de amadores d'antiguidades - no sentido clássico de 'cultores' -, como nos casos de António Augusto da Rocha Peixoto (1866-1909) e de António dos Santos Rocha (1853-1910), deixando mais sós quem, como ele, se dedicava à ciência arqueológica. Nada, porém, que o coibisse de deixar Castelo Branco após a queda da Monarquia pela qual metamorfoseou por completo os seus dias, empobrecendo também assim o universo da arqueologia em Portugal.

\section{O legado}

Com a implantação da República, F. Tavares Proença Júnior abandonou a arqueologia para abraçar a causa monárquica (Santos 2010) que o havia de conduzir ao exílio para sempre. Envolveu-se então na preparação dos levantamentos registados durante as incursões monárquicas paivenses (1911-1912). Mais do que isso, e nas palavras de seu pai, «Em 1911 apaixonou-se pela politica monarquica e em agosto d'esse anno vio-se forçado a emigrar para Hespanha. Ainda em 1911 voltou com uns amigos a Portugal e proclamaram a Monarchia em Monsanto, proximo da Fronteira» ${ }^{12}$.

Nada, contudo, que o afastasse ainda por completo da arqueologia, considerando o entusiasmo que revelou em finais de Novembro de 1910 ao prospectar artefactos na região de Chaves (Martins 2016, 56). O afastamento definitivo de Castelo Branco e da arqueologia assomou pouco depois quando, após obter «...uma portaria de louvor por ter offerecido o museu á Camara [...] t[eve] logo uma parelha de coices na alteração que ali fizeram no regulamento do Museu. E... c'est tout!..13

Orfanado e colocado à mercê de vontades alheias, como a do director do Museu Machado de Castro, recém-instituído (1911), António Augusto Gonçalves (1848-1932), que para ele pretendia transferir parte da sua colecção de arte, coube ao notário e arqueólogo Manuel de Paiva Pessoa assegurar a sobrevivência do Museu, na sua qualidade de director-interino. Reinstalou-o então na Escola Normal Primária, em 1912 , para, coadjuvado pelo vereador da Câmara Municipal, João do Nascimento Costa, o retornar à sua antiga sede três anos depois (Almeida 1973, 8).

Um conjunto de episódios que não pode deixar, em todo o caso, de surpreender pelo novo contexto político então vivido pouco indulgente para com opções ideológicas similares às tomadas recentemente por $\mathrm{F}$. Tavares Proença Júnior. Expressaria, no entanto, a pertinência do projecto museológico, cultural e científico elaborado pelo jovem arqueólogo, assim como o prestígio e o respeito alcançados pela família paterna, cuja influência económica e social seria reforçada por uma ampla rede de solidariedade familiar e de lealdades extra-familiares.

Entrementes, reencontramos F. Tavares Proença Júnior em Davos (Suíça). Decorria o ano de 1913. Aí produz uma quantidade assinalável de correspondência familiar dirigida sobretudo ao pai. Ali o visitam. Não se desvia, porém, da causa monárquica, 
embora se dedique às ciências naturais, no final da vida, vindo a falecer em La Roziaz (Suíça), a 24 de Setembro de 1916, após dois longos meses de padecimento. Enterrado em Castelo Branco, a municipalidade decidiu unanimemente «Dar ao Museu o nome de "Museu Municipal de Francisco Tavares de Proença Júnior»" ${ }^{14}$, em sessão da Comissão Executiva de 12 de Outubro. Entretanto, criara-se o grupo "Os Amigos do Museu e da Cidade”, em Setembro de 1914, destinado a assegurar o projecto museológico traçado pelo seu mentor e primeiro director.

O futuro ditou, todavia, outras sortes ao Museu e aos "Amigos do Museu" (Garcia 1962a e 1962b).

Mas estas são outras páginas de uma já longa história devedora da vida e obra de F. Tavares Proença Júnior mergulhadas, como outras coevas, no difícil caminho da arqueologia em Portugal, a exigir asserção, perseverança e resolução sustidas em pressupostos e processos sólidos. Tenacidade possível graças a uma vontade intrínseca de fazer vingar projectos e aos amplos capitais desfrutados pela sua família terratenente e respectivas redes de contacto. Um conjunto de apoios e redes que permanece com frequência invisível da historiografia, apesar de fulcral para entender decisões, procedimentos e resultados.

Somente assim e graças aos vários capitais disponibilizados pela família paterna, foi possível a F. Tavares Proença Júnior promover, em tão pouco tempo, a região de Castelo Branco e delinear um plano destinado a colocar Castelo Branco e o seu próprio nome no mapa científico português e europeu, enquanto demonstrava como a interioridade geográfica não se isolava, antes acompanhava as principais novidades transfronteiriças com as quais mantinha maior afinidade intelectual.

\section{BIBLIOGRAFIA}

“DR. ANTONIO dos Santos Rocha." 1910. Boletim da Associação dos Archeologos Portuguezes, 5. érie, XII (2): 76.

“Estudos de Castelo Branco." 1972. Revista de História e Cultura, n.ํ 40, 1 de Abril de 1972.

Almeida, Fernando de. 1973. "Museu e Diocese de Castelo Branco." Estudos de Castelo Branco. Revista de História e Cultura, 7-16.

Antunes, Luís F. 2007. "Francisco Tavares Proença Júnior: Um Arqueólogo “moderno” na Préhistória da Arqueologia Portuguesa?" Dissertação de mestrado em Arqueologia Pré-Histórica e Arte Rupestre, Instituto Politécnico de Tomar e Universidade de Trás-os-Montes e Alto Douro.

Caninas, João. 2012. “As Construções Funerárias da Pré-História na Região de Castelo Branco no Contexto da Carta Arqueológica Regional.” Projecto apresentado para obtenção do segundo ciclo de Estudos em Arqueologia, Faculdade de Letras da Universidade do Porto.

Cardoso, João Luís. 2001. “Contributos Recentes para o Conhecimento da Pré-História Recente do Sul da Beira Interior." Revista Discursos (Junho): 47-61. 
Cardoso, João Luís. 2008. "Francisco Tavares de Proença Júnior, no Quadro da Arqueologia Portuguesa do Início do século XX." In Actas do Congresso Internacional de Arqueologia “Cem Anos de Investigação Arqueológica no Interior Centro", 17-45. Castelo Branco: Museu de Francisco Tavares Proença Júnior.

Coito, Lívia Cristina. 1999. "Epistolário de José Leite de Vasconcelos.” Suplemento de O Arqueólogo Português. 1. Lisboa: Museu Nacional de Arqueologia.

Congrès International d'Anthropologie \& d'Archaéologie Préhistoriques. Compte Rendu de la Neuvième Séssion à Lisbonne, 1880. 1884. Lisbonne: Typographie de l'Academie Royale des Sciences.

Custódio, Jorge. 2013. 'Renascença' Artística e Práticas de Conservação e Restauro Arquitectónico em Portugal, Durante a I República - Património da Nação. II. Lisboa: Caleidoscópio.

Dias, José Lopes. 1954. “Tavares Proença J.or, Fundador do Museu de Castelo Branco. Apontamento da sua Vida e Obra." Sep. Seiva, 2-4 (21): 22 ill.

Dubois, Sébastien. 2011. “Émergence et Développement de l'Archéologie Préhistorique en Midi Toulousain entre XIXè et XXè Siècle. Regard sur l'Itinéraire Scientifique et Institutionnel d'Émile Cartailhac (1845-1921).” Tese de doutoramento em Pré-História, Université de Toulouse.

Fabião, Carlos. 2004. “O Arqueólogo Francisco Tavares Proença (Júnior).” In Arqueologia. Colecções de Francisco Tavares Proença Júnior [catálogo], coord. Ana Margarida Ferreira, 12-27. Lisboa: Instituto Português dos Museus.

Ferreira, Ana Margarida, coord. 2004. Arqueologia: Colecções de Francisco Tavares Proença Júnior [catálogo]. Lisboa: Instituto Português dos Museus.

Garcia, Luís Pinto. 1943. Museu Regional de Francisco Tavares Proença Júnior (Breve Descrição do). Castelo Branco: Tip. Portella Feijão.

Garcia, Luís Pinto. 1962a. "O Museu de Castelo Branco. Breve história. Descrição Sucinta.” Sep. Estudos de Castelo Branco. Revista de História e Cultura, 7-43 (26 ill.).

Garcia, Luís Pinto. 1962b. “Um Museu e um Director. Um Corpo e uma Alma." Sep. Estudos de Castelo Branco. Revista de História e Cultura, pp. 5-8.

Gonçalves, Maria Neves Leal. 2007. “A Greve Académica de 1907. Suas Repercussões Políticas e Educacionais.” Revista Lusófona de Educação (9): 61-84.

Henriques, Francisco, Salvado, Pedro Salvado, Caninas, João Caninas, e Mafalda Chambino. 2015. Apontamentos sobre a Investigação Arqueológica no Concelho de Idanha-a-Nova. ACAFA on-line, n.․ 10 .

Henriques, Francisco. 2004. O Megalitismo da Região de Castelo Branco na Obra de Francisco Tavares de Proença Júnior e Trabalhos Posteriores. Vila Velha de Ródão: Associação de Estudos do Alto Tejo.

Martins, Ana Cristina. 2003. Possidónio da Silva (1806-1896) e o Resgate da Memória. Um percurso na Arqueologia de Oitocentos. Lisboa: Associação dos Arqueólogos Portugueses.

Martins, Ana Cristina. 2005. “A Associação dos Arqueólogos Portugueses na Senda da Salvaguarda Patrimonial. Cem Anos de (trans)formação. 1863-1963.” Tese de doutoramento em História, Universidade de Lisboa.

Martins, Ana Cristina. 2009a. “António Augusto da Rocha Peixoto (1866-1909) no Contexto da Arqueologia Contemporânea (um breviário).” Boletim Cultural de Póvoa de Varzim, vol. 43: 191-210.

Martins, Ana Cristina. 2009b. “O Megalitismo no Discurso Arqueológico Português. Entre o Liberalismo e o Estado Novo: Uma Primeira e Sumária Mirada." Estudos Arqueológicos de Oeiras, 17: 607-616. 
Martins, Ana Cristina. 2012. "António dos Santos Rocha (1853-1910) e a Arqueologia na Viragem do Novo Século." In Santos Rocha, a Arqueologia e a Sociedade do seu Tempo, coord. Raquel Vilaça e Sónia Pinto, 13-39. Figueira da Foz: Casino da Figueira da Foz.

Martins, Ana Cristina. 2014. "A Sociedade Archeologica Luzitana no Contexto da Arqueologia de Oitocentos." Setúbal Arqueológica, vol. 15 - II Encontro de Arqueologia da Arrábida. Homenagem a A. I. Marques da Costa, 203-217. Setúbal: MAEDS/Assembleia Distrital de Setúbal.

Martins, Ana Cristina. 2016. "Francisco Tavares Proença Júnior (1883-1916) e a Arqueologia em Castelo Branco na Viragem para o Século XX: Textos, Contextos e (des)venturas." In 100 Anos de Arqueologia em Castelo Branco, 25-60. Castelo Branco: Sociedade Grupo de Amigos do Museu Francisco Tavares Proença Júnior.

Papanelopoulou, Faidra, Agustí Nieto-Galan, e Enrique Perdiguero, eds. 2009. Popularizing Science and Technology in the European Periphery, 1800-2000. Farnham: Ashgate.

Peixoto, António da R. 1892. “A Iniciativa Individual na Arqueologia.” Revista de Portugal, IV (21): 350-370.

Proença Júnior, Francisco Tavares de. 1908. "Sur les Mégalithes Portugais, Congrès Préhistorique de France, Autun, 1907." Compte Rendu de la Troisième Session, 510. Paris: Schleicher Frères, editeurs.

Proença Júnior, Francisco Tavares de. 1910. Archeologia do Districto de Castello Branco: $1^{a}$ Contribuição para o seu Estudo. Leiria: Typographia Leiriense.

Santos, Miguel D. 2010. A Contra-revolução na I República. 1910-1919. Coimbra. Imprensa da Universidade de Coimbra.

Sommer, Ulrike. 2009. "The International Congress of Prehistoric Anthropology and Archaeology and German Archaeology." In Archaeologists Without Boundaries: Towards a History of International Archaeological Congresses (1866-2006), ed. Mircea Babes e Marc-Antoine Kaeser, 17-31. Oxford: Archaeopress.

Vilaça, Raquel, coord. 2016. Francisco Tavares de Proença Júnior em 33 Imagens. Castelo Branco: Sociedade dos Amigos do Museu Francisco Tavares Proença Júnior.

VV.AA. 1907. Congrès Préhistorique de France. Compte Rendu de la Deuxième Session. Vannes, 1906. Vannes: P. Schleicher Frères.

\section{NOTAS}

1. A autora escreve de acordo com a antiga ortografia.

2. A primeira metade de Oitocentos primara, entre nós, pelo combate intelectual por uma lei protectora dos monumentos, ponderando-se constituir uma comissão de salvaguarda monumental com inspectores ou comissões de inspectores nas capitais distritais. Procurava-se dar, assim, os primeiros passos neste âmbito, criando-se, por exemplo o fugaz Real Instituto Arqueológico de Portugal (1868), anos antes de o Ministro do Reino, António Rodrigues Sampaio (1806-1882), nomear uma Comissão para estudo da defesa monumental, desenvolvimento arqueológico e reforma artística (1875), dissolvida pouco depois (1877), com a sua saída do Governo. Assim se confirmava quanto os projectos nesta área dependiam, quase em exclusivo, de interesses e empenhos pessoais.

3. Exemplo do naturalista Francisco Arruda Furtado (1854-1887), na sua correspondência com Charles Darwin (1809-1882). 
4. Informação contida em carta endereçada a J. Leite de Vasconcelos, a partir da Quinta da Cortiça, Leiria, com data de 30 de Setembro de 1906 ("Epistolário de José Leite de Vasconcelos". 2776 - Júnior, Francisco Tavares Proença, 19227 1/2).

5. Propósito repetido pouco depois, em carta enviada a J. Leite de Vasconcelos, datada de 1 de

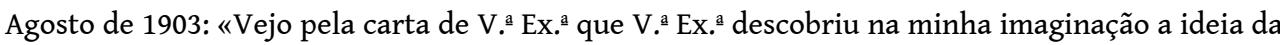
fundação de um museu em Castello Branco. É essa effectivamente a minha ideia. Cumpre-me agora dizer a V. Ex. a uma coisa: é que todas as pesquisas e excursões que tenho feito são apenas com o fim de reunir materiaes para a fundação de esse Museu» (2776, 19212 2/2, itálico da autora).

6. Transcrição de carta enviada ao pai em Agosto de 1909, contida em Estudos de Castelo Branco. Revista de História e Cultura, n. 40, 1 de Abril de 1972.

7. “Epistolário de José Leite de Vasconcelos”. 2776 - Júnior, Francisco Tavares Proença, 192777+7. 18 de Fevereiro de 1911. Anos antes, em 1906, em carta dirigida a este mesmo arqueólogo, F. Tavares Proença Júnior mencionava tencionar «se a Camara Municipal puzesse á minha disposição uma ou duas sallas, depositar n'ellas a minha collecção, e a pouco e pouco ur recolhendo para ali os objectos que fosse obtendo, formando assum um museu municipal, como já teem tantas outras terras do nosso paiz. Gradualmente esse pequeno museu iria tomando incremento e progredindo, e por essa fórma salvar-se-hiam muitos objectos que constantemente estão sendo destruidos pelas populações mais barbaras do que os antepassados invasores» [carta datada de 30 de Setembro de 1906 (2776, 19227 1/2)].

8. «Apresentei hontem officialmente á Camara a ideia da creação de um Museu Municipal. Segundo me informa o Presidente, será approvada na proxima sessão e será pedida ao Governo para a instalação a capella do antigo convento de St.. António d'esta cidade. // No officio que dirigi á Camara, mostrei as vantagens que resultariam da creação de um M. Municipal e colloquei-me inteiramente á sua disposição para: // 1.ำ Dirigir a instalação dos objectos no museu, offerecendo-lhe parte da minha collecção e depositando lá a outra parte. // 2.․ promover o desenvolvimento do M. quer continuando a realizar explorações e a recolher os objectos depois de serem estudados e salvos da destruição, quer chamando para o museu a attenção dos estudiosos, etc.» (“Epistolário de José Leite de Vasconcelos”. 2776 - Júnior, Francisco Tavares Proença, 19245 2/2 e 3/3. 27 de Março de 1908).

9. Embora sem a presença de figuras nacionais, como a de J. Leite de Vasconcelos, que visitaria o museu apenas no Verão de 1916, ironicamente poucas semanas antes do falecimento de F. Tavares Proença Júnior -, o evento foi noticiado na imprensa diária, a exemplo de $O$ Século, no seu número 10 182, de 20 de Abril, com fotografia de F. Tavares Proença Júnior no seu gabinete de trabalho. F. Tavares Proença Júnior acalentara, porém, que fosse o primeiro a visitá-lo: «... peço a V. Ex..$^{a}$ um pedido. V. ${ }^{\underline{a}}$ Ex. ${ }^{\underline{a}}$ hade dar-me a honra de sêr o primeiro visitante, ou dos primeiros, a inscrever o seu nome entre os dos que lá os deixarem no dia de abertura», segundo informação contida em carta endereçada a J. Leite de Vasconcelos, a partir da Quinta da Cortiça, Leiria, com data de 30 de Setembro de 1906 (“Epistolário de José Leite de Vasconcelos”. 2776 - Júnior, Francisco Tavares Proença, 19227 2/2, itálico da autora).

10. Caso da Portugalia: Materiaes para o Estudo do Povo Portuguez (Porto, 1899).

11. Em carta escrita a J. Leite de Vasconcelos, a partir da Quinta da Cortiça, a 26 de Agosto de 1907 (“Epistolário de José Leite de Vasconcelos”. 2776 - Júnior, Francisco Tavares Proença, 19223 $1 / 2)$.

12. "Epistolário de José Leite de Vasconcelos". 2775 - Proença, Francisco Tavares d'Almeida, 19199B 1/4. Tratar-se-á da portaria da Direcção Geral da Administração Política e Civil, 1. a Repartição, publicada no Diário do Governo de 02-05-1910 (Dias 1954, 10).

13. "Epistolário de José Leite de Vasconcelos". 2776 - Júnior, Francisco Tavares Proença, 192777+7. 18 de Fevereiro de 1911.

14. Transformado em 'Museu Regional Tavares Proença J.or' pelo decreto n.o 16.578, Diário do Governo, n.ํ53, 1. a série, de 06-03-1929 (Dias 1954: 10). 


\section{RESUMOS}

Inaugurado em 1910, o Museu Municipal de Castelo Branco nasceu da vontade e da acção de Francisco Tavares Proença Júnior (1883-1916), então com 27 anos. Pertencendo a uma das mais influentes famílias beirãs da época, F. Tavares Proença Júnior cedo se interessou pelo passado da região onde residia, percorrendo-a em demanda de sítios arqueológicos que assinalou e de artefactos que reuniu para com eles constituir uma colecção. Esta colecção estará na base do museu que projectou instituir desde 1902, por entre múltiplos apoios, desalentos e contradições. Tratou-se, contudo, de um plano individual de visibilidade pública que merece ser analisado enquanto materialização de uma agenda de afirmação pessoal alicerçada nos capitais granjeados por sua família, assim como nas diferentes tipologias de redes - incluindo territoriais -, e estratégias interpessoais tecidas ao longo dos tempos pelos seus antepassados e colaterais. Propomos, por conseguinte, demonstrar neste artigo a relação que foi sendo mantida entre o indivíduo F. Tavares Proença Júnior e os capitais, o território, a colecção, e museu e identidade(s).

Inaugurated in 1910, the Municipal Museum of Castelo Branco was born from the will and action of Francisco Tavares Proença Júnior (1883-1916), then 27 years old. Belonging to one of the most influential families of the time, F. Tavares Proença Júnior soon became interested in the past of the region where he lived, going through it in search of archaeological sites he pointed out and artefacts that he collected in order to constitute a collection that would be at the base of the museum that he planned to institute since 1902, regardless of multiple discouragements and contradictions. It was, however, an individual plan of public visibility that deserves to be analyzed as a materialization of an agenda of personal affirmation based on fundings provided by his family. We propose, therefore, to demonstrate, in this article, the relationship maintained between the personality F. Tavares Proença Júnior, his incomes, territory, collection, museum and identity(s).

\section{ÍNDICE}

Keywords: Francisco Tavares Proença Júnior, biography, Museum Francisco Tavares Proença Júnior, collecting, museum history, archaeology collections

Palavras-chave: Francisco Tavares Proença Júnior, biografia, Museu Francisco Tavares Proença Júnior, história dos museus, coleções arqueológicas

\section{AUTOR}

\section{ANA CRISTINA MARTINS}

Investigadora do Instituto de História Contemporânea (Faculdade de Ciências Sociais e Humanas da Universidade Nova de Lisboa) e antiga bolseira de pós-doutoramento da Fundação para a Ciência e a Tecnologia com o projecto "Arqueologia em Inovação num Portugal em Transição: Actores, Instituições e Projectos (1958-1977)”, tendo como unidade de acolhimento o Instituto de História Contemporânea da Universidade Nova de Lisboa - Grupo de Investigação Ciência, Estudos de História, Filosofia e Cultura Científica (Universidade de Évora). É investigadora colaboradora do Centro de Arqueologia da Universidade de Lisboa, instituição onde se doutorou em História (História da Arte), obteve o mestrado em Arte, Património e Teoria do Restauro, e se licenciou em História, variante de Arqueologia. É autora de inúmeros títulos sobre a história da evolução do 
pensamento arqueológico, museológico e patrimonial. Preside à Secção de Arqueologia da Sociedade de Geografia de Lisboa e vice-preside à Assembleia Geral da Associação dos Arqueólogos Portugueses.

Instituto de História Contemporânea (IHC), Polo de Évora, Palácio do Vimioso, Largo Marquês de Marialva, 8 - 7000-809 Évora, Portugal, acmartins@uevora.pt 